\title{
Addiction Abstinence as an Accessible Experience: A Phenomenological Study
}

\author{
Heidarali Abedi, ${ }^{1}$ Mehri Nasiri Rizi, ${ }^{1}$ Ali Mohammadi Nasrollah, ${ }^{2}$ Arash Ghodoosi, ${ }^{1}$ and Ali Navidian ${ }^{3,}$ \\ ${ }^{1}$ School of Nursing and Midwifery, Islamic Azad University, Khorasgan Branch, Isfahan, IR Iran \\ ${ }^{2}$ School of Nursing \& Midwifery, Isfahan University of Medical Sciences, Isfahan, IR Iran \\ ${ }^{3}$ Pregnancy Health Research Center, Zahedan University of Medical Sciences, Zahedan, IR Iran \\ "Corresponding author: Ali Navidian, Pregnancy Health Research Center, Zahedan University of Medical Sciences, Zahedan, IR Iran. Tel: +98-5433442482, E-mail: \\ alinavidian@gmail.com
}

Received 2015 July 07; Revised 2016 January 31; Accepted 2016 May 11.

\begin{abstract}
Background: Individuals' experiences following addiction abstinence may have different meanings from the former addict's perspective, demanding careful scrutiny to understand such experiences.

Objectives: This study aimed to explore and explain the meaning of the lived experiences of addicts after sobriety.

Patients and Methods: This descriptive phenomenological study aimed to describe the experiences of individuals who had stopped using drugs. The participants were 10 members of narcotics anonymous (NA) in Lenjan, Iran, who were recruited using the purposive sampling method. To gather the data, unstructured, in-depth interviews were carried out. The interviews were recorded on cassette tapes with the consent of the participants, and the collected data were analyzed using Colaizzi's method.

Results: The results of this study were presented in the form of 48 codes and included the four main themes of detour, gateway, metamorphosis, and leadership. These represent the general structure of the individuals' lives after recovery.

Conclusions: Our findings revealed that specific factors, such as recall of sustained suffering in the course of recovery, members' contribution, being part of a community, participation in collective classes, feelings of equality and co-leveledness, observation of others' success, and rethinking, played significant roles in addiction recovery.
\end{abstract}

Keywords: Behavior, Addictive, Substance Withdrawal

\section{Background}

The problem of drug addiction has attracted a lot of attention, and different societies have tried to solve it (1). In spite of scientific advances and the public's increasing level of awareness, addiction is still expanding, and many people become addicted to drugs each year (2). According to the world health organization report from 2011 and based on United Nations office of drugs and crimes statistics, the global number of addicts has exceeded 200 million people (3). Moreover, studies have shown that the prevalence and incidence of substance abuse and the related disorders are presently increasing in our country (4). About 104,000 - 263,000 deaths occurring in 2011 were speculatively attributed to drug abuse (5).

There is a general perception that addiction is not completely curable and has an unrecoverable loss of control as its main characteristic. Thus, recovery from addiction does not merely involve improvement of the addict's physical status; rather, it comprises the availability of growth in all humanitarian dimensions, that is, continuous creative movement toward changing one's feelings; improving one's attitude toward and perceptions about the self, others, and God; and daily life issues (2). This is why elim- inating drug use has been always the crux of attention for the authorities in charge, the addicts themselves, and addicts' families (6).

The major problem in the treatment possess of addicts is the risk of relapse (7). Many people consider recovery to be an exception for those who have been drug abusers for a long time, as addiction is considered as an untreatable issue (8).

A recent research has shown controversial results concerning the decreased enthusiasm in patients under treatment (9). At present, one of the major challenges in the MMT is the degree of retention in treatment and the prevention of addiction relapse (10). Studies have shown that $20 \%-90 \%$ of the addicts under treatment will relapse (11). Mutasa (2001) and Elgeili and Bashir $(2005)(12,13)$ reported a relapse rate of over $50 \%$ within a year, while Gossop et al. (2002) and Pringle et al. $(2002)(14,15)$ found the relapse rate to be over $60 \%-70 \%$ within a year. A study that was carried out in Iran showed that the relapse rate in patients under the MMT is $48.2 \%$ (16).

The increasing number of substance abusers indicates that the applied therapeutic methods have not been effective enough. As a social pathology of human society, ad- 
diction has endangered the safety of youth. Hence, there needs to be a fundamental revision of the methods for preventing, controlling, and fighting drug abuse. In the present researchers' view, to address this need, we can rely on information based on addicts' experiences to provide an in-depth description of the phenomenon of drug and substance withdrawal. This study was conducted to describe the experience of recovered addicts after withdrawal using the phenomenological method.

\section{Objectives}

The present study aimed to explore the concept of addiction abstinence from the perspective of former drug users' experiences, since an understanding of these attitudes can play a significant role in providing the required knowledge to experts in this field. This can lead to improved intervention methods and more comprehensive treatments. The study also aimed to explore the meaning of experiences of addicts after they attain sobriety.

\section{Patients and Methods}

Since this study aimed to explore the lived experiences of the individuals participating in addiction recovery programs, the qualitative descriptive phenomenological method was used. A qualitative framework encompasses a systematic abstract procedure that suitable for describing lived experiences and exploring their meanings. Phenomenology is a method of reflecting on human lived experiences where the researcher's main focus is on the individuals' experiences related to the phenomenon of interest.

The inclusion criteria were: individuals' ability to express their feelings and thoughts about addiction recovery, membership in narcotics anonymous (NA), physical health, individuals' interest in participating in the interviews, and having a one-year interval from recovery.

The purposive sampling method was used for participant selection. As the number of participants in phenomenological studies can greatly depending on availability of participants, type and richness of data, and time limitations, data saturation in the current study occurred after interviewing 10 participants. Since there is no specific guidance for determining the number of participants in qualitative studies, the sample size is determined during the study. Indeed, in qualitative studies, the study is more focused on the quality and richness of the gathered data than the sample size.

Unstructured, in-depth interviews were used for data collection. The research project was approved by the re- search ethics committee at the school of nursing and midwifery, Islamic Azad University, Khorasgan Branch, Isfahan, Iran. The researchers obtained permission from the cultural center and written informed consent from the participants. The interviews were then carried out and recorded on cassette tapes with the consent of the participants. The interviews were conducted in a quiet milieu with experienced interviewers who were skilled at starting the interview using appropriate greetings and creating reciprocal confidence and co-construction. The interviewees were guaranteed anonymity and confidentiality, and they were asked to express their experiences concerning addiction recovery. The researchers then conducted the interview through co-construction by asking more questions on the issue. If necessary, they used short-answer questions as well. A unique number was given to each interview. Each interview lasted about 30 - 60 minutes and recorded on cassette tapes with the consent of the participants. The researchers listened to the interview recordings several times and immersed themselves in the data; following this, the interviews were transcribed verbatim. Ongoing data analysis was conducted along with data collection; the data were analyzed using Colaizzi's method, and they were grouped into themes after the initial categorization of the extracted codes. Finally, the analytical process was completed after all interviews were finished.

In the current study, credibility was established through prolonged engagement with participants. This involved long-term continuous observations of withdrawers' behavior, member checking, peer debriefing, and review of data analysis with other members of the research team.

For dependability, coding of the interviews was carried out by other colleagues who were experienced in coding qualitative data. Moreover, the researchers documented the research details to facilitate a possible of external audit. In addition, informative description of the participants and the research situation was offered by the researchers. To achieve neutrality and objectivity, bracketing was used. Furthermore, to increase the transferability of the data to similar groups, the researchers described the research process thoroughly and selected the most heterogeneous participants.

\subsection{Data Analysis}

Different scholars have reported various methods of data analysis that can be used to analyze phenomenological data. Among them, Streubert and Carpenter introduced Colaizzi's method of phenomenological data analysis (17). This represents a seven-step process that is valid and logical for analyzing data using descriptive phe- 
nomenological approach (18). Hence, this study used Colaizzi's method for data analysis.

\subsection{Ethical Considerations}

Ethical considerations were upheld in this study. The researchers informed all participants about the objectives of the study by telling them about the study design and assuring them of their anonymity and the confidentiality of their data, as well as their ability to withdraw their participation at any time; following this, informed consent was obtained from all participants. The respondents were also guaranteed the right to refuse to answer any question or stop the interview at any time. Data from the recordings were stored securely.

\section{Results}

In this study, the researchers listened to the interview recordings many times and transcribed them verbatim. Then, significant statements related to the intended concept under study that is, addiction recovery were extracted from each interview and coded. On the whole, 10 interviews were performed with three females and seven males aged 27 - 40 years. The participants' education levels varied from the fifth grade of primary school to master's degrees. Data collection lasted for two months, and a total of 897 significant statements were obtained. Next, the underlying meaning of each significant statement was extracted and written in the form of formulated meaning. Gradually, the obtained meanings were categorized based on their similarities. In this way, primary concepts and sub concepts were formed. Regarding the conceptual similarities among the concepts, 48 primary codes were acquired.

\subsection{Stage 1}

The interview texts were transcribed verbatim and read many times to become familiar with them. For example, Participant 5 asserted, When someone is talking about addiction on the radio, TV, etc., I burst out crying. I can feel what they are talking about in all the cells in my body. These two types of life are interesting to me; first, I experienced ecstasy and then the pleasure of a new life, with new value bestowed on me. For instance, one day, I was talking to one of my friends who is now leading a good life, saying, "Nothing can make me happy any more than seeing the fruits of your efforts, at least you've acquired an experience which is useful for everybody."

\subsection{Stage 2}

In this phase, the researcher assessed each statement and underlined the important sentences related to the phenomenon under study to extract meaningful information. This was done for the previous passage as follows:

When someone is talking about addiction on the radio, TV, etc., I burst out crying. I can feel what they are talking about in all the cells in my body. These two types of life are interesting to me; first, I experienced ecstasy and then the pleasure of a new life, with new value bestowed on me. For instance, one day, I was talking to one of my friends who is now leading a good life, saying, "Nothing can make me happy any more than seeing the fruits of your efforts, at least you've acquired an experience which is useful for everybody."

\subsection{Stage 3}

In this phase, to abstract important concepts, all concepts were reviewed several times. This phase is known as the "concept formulation process." A total of 897 primary codes were extracted from the underlined statements related to the phenomenon under investigation. For example, the following primary codes were extracted from the aforementioned statements of the participant:

- Feeling the phenomenon of addiction in the individual's body cells;

- Experience of life at the peak of ecstasy;

- Experience of life at the peak of usefulness; and,

- Satisfaction with sharing one's own experience with others and saving them.

\subsection{Stage 4}

In this phase, the researchers reviewed the primary codes from the first stage many times, organized the formulated concepts within subject categories, and clustered them; in this way, the second-level conceptual codes were acquired. For instance, the concepts of subject category of "gift of recovery" were formed by integrating the codes of "enjoying the sunrise," "observing family satisfaction," "experiencing life at the peak of usefulness," "the individual's inducement for learning after recovery," and "the person's entrance into the community after withdrawal," all of which indicate the participants' achievements after recovery. Ultimately, 48 organized concepts were obtained, including "entrance into recovery," "rethinking," "drug abuse experience," "the end of the line," "the price of drug abuse," "useless measures," "destruction of spirituality," and "the emergence of new beliefs."

Stage 5: In this phase, categories labeled "themes" were formed (Table 1). For instance, "destruction of spirituality," "physical crises of the abuse period," "destruction of 
values," and so on were integrated to form the "detour" theme.

All of the acquired concepts formed the main concepts of this study after this stage was complete. Together, these constitute the components of the constructive structure of individuals' experience after withdrawal.

\subsection{Stage 6}

The collection of the four themes formed the main concepts related to the purpose of the study.

\subsection{Stage 7}

In this stage, that is, Colaizzi analysis, the researchers consulted with the participants to confirm that the analysis described their experiences. The final validity of the data was determined in this way.

\section{Discussion}

The main goal of this study was to explore the post recovery lived experiences of former users. It can be said that these experiences were manifested in four main themes, namely detour, gateway, metamorphosis, and leadership. Following these themes, concepts were identified from participants' post recovery experiences. If these findings are compared to those of other research, a general summery can be acquired. Below, each theme is discussed in detail.

\subsection{Theme 1 Detour}

The participants of the study reported that they had exited slowly from the main path of life at a certain point and entered the new phase of life without tangible changes, and this was similar to a downward spiral. Passing through this phase was slow for some individuals and faster for others. Because this detour caused a big gap between the individual and their normal daily living, all of them perceived that time and energy would be needed to come back to the main path of life and consequently to live a normal life like others around them were doing. This detour was considered an abnormal path leads to a point referred to as "the end of line." Some of the participants' comments relating to this theme are as follows:

I had just been released from jail, and I thought of suicide very much. I mean, when I abused substances, I cried and walked aimlessly in streets. I noticed that other people stared at me, but the world was meaningless for me. I remember that this was my state during the last two or three nights (Participant 9).

I was a university student when my addiction became acute. I had an exam and had not abused substances. We went there and the prof had said that he would come at 5 pm. I left there and came back to find drugs. I went to a distant place and searched for the person who provided me with substances. I'll never forget it; I was standing there shivering, and I was also depressed. Then, I cursed myself and asked: "What are you doing here? Who has brought you here? You should be at the university." (Participant 6).

"Detour" consisted of the following concepts: abuse experience, the end of the line, the price of abuse, useless measures, physical crises of the abuse period, social crises of the abuse period, familial crises of the abuse period, economic crises of the abuse period, work crises of the abuse period, the individual's internal crises, response to the last call of abuse, and the last farewell. Below, examples of the method of formation of this theme from sub concepts and its comparison with previous studies are provided.

\subsubsection{The End of the Line}

Most participants stated that at the end of their drug abuse, they hated addiction for any other reason and had reached a dead end in their lives. They reached a point that was the so-called "end of the line." One participant reported the following:

I began to cry and said: "Oh my God, please kill me." It was the first time that I said it. I went and performed ablution and said some prayers. I said two parts of my prayers and pleaded: "Oh God, either kill me or save me." (Participant 1).

\subsection{Theme 2 Gateway}

The participants stated that after years of efforts to recover and failure for many reasons, they formed a new belief that abstaining from drug use was no longer possible anymore. They had heard many times that they could recover if they wanted to badly enough, but their greatest efforts had not succeeded: It was in 1991 that I decided to quit, so I went to the doctor. Many times I stopped using, but I was not able to sustain my abstinence, so that it took 14 years to quit for good" (Participant 1 ).

What became clear in this study was that to reach the point of freedom, certain instruments, tools, and information are required that these individuals were lacking. Thus, their efforts reached a dead end at some point and their cravings captured their attention, driving them to reabuse: "I stopped many times; that part was not difficult for me. Yet the temptation prevented me from abstaining" (Participant 10).

As mentioned above, the main concept of gateway consisted of several categories, including the following: entrance into withdrawal, friends' attention, the safe coast, feelings of similarity, abandonment, test of motivation, spiritual status at the beginning of recovery, temptation, 
Table 1. Third-level Codes Extracted from the Interview Text in Stage 5 of Colaizzi's Method

\begin{tabular}{ll}
\hline Themes & Second-Level Codes \\
\hline Detour & $\begin{array}{l}\text { Experience of drug abuse, the end of line, price of abuse, useless measures, physical crises of the abuse period, social crises of the abuse period, } \\
\text { familial crises of the abuse period, economic crises of the abuse period, destruction of spirituality, covering defects, the last farewell }\end{array}$ \\
\hline Gateway & $\begin{array}{l}\text { Entrance into abstinence, emergence of a new belief, attention of friends, safe coast, feeling of similarity, abandonment, test of motivation, } \\
\text { spiritual status at the beginning of withdrawal, temptation, unstable happiness, detoxification, rusty empty pockets, simple pain-control skills }\end{array}$ \\
\hline Metamorphosis & $\begin{array}{l}\text { Gradual improvement of physical status, mental awareness, gift of recovery, supporting hands, transmission of experience, awakening of } \\
\text { conscience }\end{array}$ \\
\hline Leadership & Price of abstinence, contribution, secrets of flight, rethinking \\
\hline
\end{tabular}

unstable happiness, detoxification, disparity in pains, purity, chains on the wings of flight, and simple pain control skills. Below, examples are given of how this theme was formed from categories and comparison with other studies.

\subsubsection{Entrance Into Abstinence}

In the present study, each of the participants expressed different experiences related the phase of entrance into recovery; some considered it a miracle, while most considered adherence to the right path and entrance into recovery as guidance from God. Some attributed their recovery to observing the success of their friends. However, others had decided beforehand to enter the recovery program and entered it after some enquiry. One participant commented, "It seemed that it was from God's side that everything was ready for me to quit, like the clouds and temperature that are prerequisites for rain. I was ready to ask God for help" (Participant 1).

\subsubsection{Emergence of a New Belief}

Most participants stated that at the time of their last recovery, they had found a new belief that had caused them to follow the path to recovery with confidence. Belief refers to the individual's attitude towards the final result of any undertaking and the value attached to this eventuality. Information is changed into attitudes when it leads to an individual's satisfaction with self the or when it increases self-confidence and improves one's attitudes and helps one to maintain oneself as an able person.

\subsection{Theme 3 Metamorphosis}

The participants stated that they had no accurate information about their problem and its solution before they stopped using drugs for the last time. They had obtained their knowledge in this regard from individuals whose information was incomplete and inaccurate. One of the elements of their success in their last recovery attempt was acquiring appropriate, accurate information from individuals who had experienced substance abuse problems in their lives and felt its effect:

I was much less disappointed this time, as there was always a source of available help. I was hopeful that if I was well, I could speak somewhere. At first, I did not speak at NA, but as I gradually began to speak, I experienced better days. My fears had gone, and this allowed me to speak more; as a result, I was gifted with a better day (Participant 7).

The term "metamorphosis" was assigned to this part of the results. The theme consisted of the following concepts: gradual improvement of physical status, mental awareness, gift of recovery, supporting hands, transmission of experience, and awakening of conscience. The examples below show how this theme was formed from the categories and comparison with previous studies.

\subsubsection{Mental Awakening}

Most participants stated that a layer of dust was gradually cleared from their minds; a kind of mental and intellectual therapy occurred, and reality gradually became clearer. They said that the blurred vision of their minds had gone away and their memories had improved. No study was found in this regard, so this study represents the only research to address this theme. One participant stated:

I looked and asked why has the color of the curtain changed? My sister's husband was there and said: "It is the same as it was before you went." I asked: "You mean it's the same color as before?" I lived in that house for three years, but I had not noticed the color of the curtain." (Participant $5)$.

\subsubsection{The Gift of Abstinence}

This theme is not consistent with other studies. Sharq et al. (19) referred to a group of factors that cause relapse, including personal, familial, social, cultural, and economic factors; they stated that individuals relapse when they fail to grow in these areas. In the study by Mirzaei et al. (6), psychological factors are mentioned as 
the most important causes of relapse, and other factors were also considered significant in the return to addiction. One participant made the following comments: "I specifically enjoy a good feeling in some parts of my affairs. Apart from the salary I receive at the end of month, when I think that I'm useful, I get a pleasing feeling. I feel satisfied" (Participant 8).

\subsection{Theme 4 Leadership}

The fourth theme to emerge was "leadership," consisting of the price of recovery, contribution, secrets of flight, and rethinking. One participant noted:

The mental challenges are endless, yet, there are certain tools that can be obtained by entering this program. We learn them and they help us not to return to addiction. Our disorder is such that we can arrest it, but we cannot treat it completely." (Participant 5).

This theme was formed from the sub concepts and comparison to other studies as illustrated below.

\subsubsection{Secrets of Flight}

Most of the participants enumerated many factors as the causes of their success in recovery, including help from family, the availability of NA and classes, undertaking the 12 steps, using the experience of other addicts, acquiring communicative skills, gaining power, the ability to say "no" to substances, and so on. Other studies have indicated failure in the mentioned items as the cause of a return to substance abuse, as mentioned above. Dickens et al. mentioned the processes that are required for recovery but are not available (20). The themes obtained from the description of the structure in this study were as follows: selfcommunication; communication with others; motivation; and the past, present, and future temporal structure. The themes were obtained by integration of structure and nature were as follows: spirituality, the end of the line, wandering, the ends, comparison of the present to the past, the progress of evolution, and inter-personal communications. This study suggests that an understanding of drug users' needs in the first phase of recovery requires support, including employment, meeting educational and occupational needs, familial support, and support groups in recovery. In the qualitative study by Taylor (21), the results showed useful findings in individuals who applied correct nutrition, sufficient exercise, and spirituality in their recovery process.

\subsection{Conclusion}

According to the findings of this study, the following factors were the most important elements in addicts' success when it came to remaining in the recovery program: having a society (NA), a feeling of equality, a sense of responsibility, no blame, giving love, feelings of sympathy, having the same story, observation of others' success in recovery, and contribution of the NA members. Of course, other factors, such as group meetings, encouragement of newcomers, and activity in the NA meetings, greatly affected the success of the recovery program. In addition, promoting the spiritual beliefs of the individuals enhanced their success positively. As a whole, the mentioned items can be considered the success factors of NA demonstrating how this therapeutic modality promotes recovery among former addicts.

\section{Acknowledgments}

The researchers express their special thanks to all the participants of this study and their families for coping with the difficulties involved in this research project. We would also like to express our special thanks to the deputy-inresearch of the Islamic Azad University, Khorasgan Branch, Isfahan, Iran.

\section{Footnotes}

Authors' Contribution: First author (Dr. Heidarali Abedi): conceptualization and design of the study, data collection, and data analysis and interpretation; second author (Mehri Nasiri Rizi): conceptualization and design of the study, data collection, and data analysis and interpretation; third author (Dr. Nasrollah Ali Mohammadi): conceptualization and design of the study, article preparation, data collection, and data analysis; fourth author (Dr. Arash Ghodoosi): article preparation, data collection, and data analysis; fifth author (Dr. Ali Navidian): conceptualization and design of the study, final approval of the article.

Funding/Support: This study was funded by the vice chancellor for research, Islamic Azad University, Khorasgan Branch, Isfahan.

\section{References}

1. Oraki M, Mokri A, Kiaei Ziabari SM. Relationship between craving for methamphetamine and personality characteristics among patients in MMT program. Iran J Psychiatr Clin Psychol. 2014;19(3):177-86.

2. Saberi Zafarghandi MB. Challenges in mental health and addiction in Iran. Iran J Psychiatr Clin Psychol. 2011;17(2):157-61.

3. Larkan M. .A study of abuse recovery programs: perceptions of mothers in recovery. Providence Rhode Island. 2010.

4. Rahimi Movaghar A, Mohamad K, Razaghi A. The 30-year-old process of Substance abuse in Iran. J Hakim Res. 2002;5(3):171-81.

5. Vazirian M. A review on drug demand reduction in Iran and recommendations for strategic development programs. Social Welfare Quarter. 2003;3(9):145-201. 
6. Mirzaei T, Ravari A, Hanifi N, Miri S, Haghdost Oskoei SF, Mirzaei Khalilabadi S. Factors associated with relapse Addiction From the perspective of people with substance abuse Referred to a drug rehabilitation center in Rafsanjan. Iran J Nur. 2010;23(67):1-11.

7. Kelly SM, O'Grady KE, Mitchell SG, Brown BS, Schwartz RP. Predictors of methadone treatment retention from a multi-site study: a survival analysis. Drug Alcohol Depend. 2011;117(2-3):170-5. doi: 10.1016/j.drugalcdep.2011.01.008. [PubMed: 21310552].

8. Domino KB, Hornbein TF, Polissar NL, Renner G, Johnson J, Alberti $S$, et al. Risk factors for relapse in health care professionals with substance use disorders. JAMA. 2005;293(12):1453-60. doi: 10.1001/jama.293.12.1453. [PubMed: 15784868].

9. Badger GJ, Bickel WK, Giordano LA, Jacobs EA, Loewenstein G, Marsch L. Altered states: the impact of immediate craving on the valuation of current and future opioids. J Health Econ. 2007;26(5):865-76. doi: 10.1016/j.jhealeco.2007.01.002. [PubMed: 17287036].

10. Fareed A, Vayalapalli S, Stout S, Casarella J, Drexler K, Bailey SP. Effect of methadone maintenance treatment on heroin craving, a literature review. J Addict Dis. 2011;30(1):27-38. doi: 10.1080/10550887.2010.531672. [PubMed: 21218308].

11. Wallace J. Theory of 12-step oriented treatment. New York: The Guilford Press; 2003.

12. Mutasa HC. Risk factors associated with noncompliance with methadone substitution therapy (MST) and relapse among chronic opiate users in an Outer London community.JAdv Nurs. 2001;35(1):97107. [PubMed: 11442687].

13. Elgeili ES, Bashir TZ. Precipitants of Relapse Among Heroin Addicts. Addict Disord Their Treat. 2005;4(1):29-38. doi: 10.1097/00132576200503000-00005.
14. Gossop M, Stewart D, Browne N, Marsden J. Factors associated with abstinence, lapse or relapse to heroin use after residential treatment: protective effect of coping responses. Addiction. 2002;97(10):1259-67. [PubMed: 12359030].

15. Pringle JL, Edmonston LA, Holland CL, Kirisci L, Emptage NP, Balavage VK. The role of wrap around services in retention and outcome in substance abuse treatment: findings from the wrap around services Impact study. Addict Disord Their Treat. 2002;1(4):109-18. doi: 10.1097/00132576-200211000-00001.

16. Afsar A, Bashirian S, Poorolaja J, Hazavehei SM, Vatan Nawaz E, Zinat Motlagh F. Predictive factors of relapse among patients treated with MMT referred to addiction centers in Hamadan based on health belief model. J Health Syst Res. 2014:2034-45.

17. Streubert HJ, Carpenter DR. Qualitative Research in Nursing. 4 ed. Philadelphia: Lippincott Co; 2007.

18. Burns N, Grove SK. The practice of nursing research critique and utilization. 6 ed. Missouri: Elsevier saunders; 2009.

19. Sharg A, Shakibi A, Neisari R, Aliloo L. Survey of Factors Rlated to The Relapse of Addiction From View of Addict Patients Attending to Drug Abuse Treatment Clinics In West Azarbaijan. Urmia Med J. 2011;22(2):129-36.

20. Dickens JR, Vail T, Persky B, Schneiders S. The experiance of recovery from Alchohol /Drugs (AOD). Harold Abel School of Social and behavioral sciences; 2011.

21. Taylor DL. The experience of recovery from addiction for people who have added a healthy diet and an exercise plan, and developed spirituality as dimensions of their recovery process: A phenomenological study. USA: Capella University; 2010. 